\title{
Photoredox-Mediated, Nickel-Catalyzed Trifluoromethylthiolation of Aryl and Heteroaryl lodides
}

\author{
Christopher S. Gravatt*, Jeffrey W. Johannes and Avipsa Ghosh* \\ Chemistry, Oncology R\&D, AstraZeneca, 35 Gatehouse Drive, Waltham, MA 02451, United States
}

Supporting Information

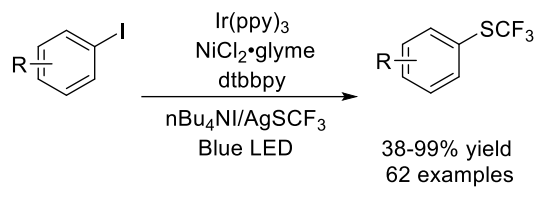

\begin{abstract}
While the area of trifluoromethylthiolation of aryl halides has been extensively explored, the current methods require complex and/or air-sensitive catalysts. Reported here is a method employing a bench-stable nickel(II) salt and an iridium photocatalyst that can mediate the trifluoromethylthiolation of a wide range of electronically diverse aryl and heteroaryl iodides, likely via a $\mathrm{Ni}(\mathrm{I}) / \mathrm{Ni}(\mathrm{III}) \mathrm{catalytic}$ cycle. The reaction has broad functional group tolerance and potential for application in medicinal chemistry, as demonstrated by a latestage functionalization approach to access (racemic)-Monepantel.
\end{abstract}

Aryl $\mathrm{SCF}_{3}$-containing compounds are important building blocks for the pharmaceutical and agrochemical industry due to the unique properties associated with the trifluoromethylthio $\left(\mathrm{SCF}_{3}\right)$ functional group. The $\mathrm{SCF}_{3}$ functional group has a very large Hansch lipophilicity parameter $(\pi=1.44)$ for its size, making it a useful moiety in the design of bioactive compounds capable of crossing the lipid membrane. ${ }^{1}$ Aryl $\mathrm{SCF}_{3}$ containing compounds are well represented in both pharmaceutical and agrochemical molecules ${ }^{1}$ (Scheme 1), highlighting the need for a robust, straightforward methodology to access this functionality.

Scheme 1. Industrially and Pharmaceutically Relevant $\mathrm{Aryl} \mathrm{SCF}_{3}$ Compounds

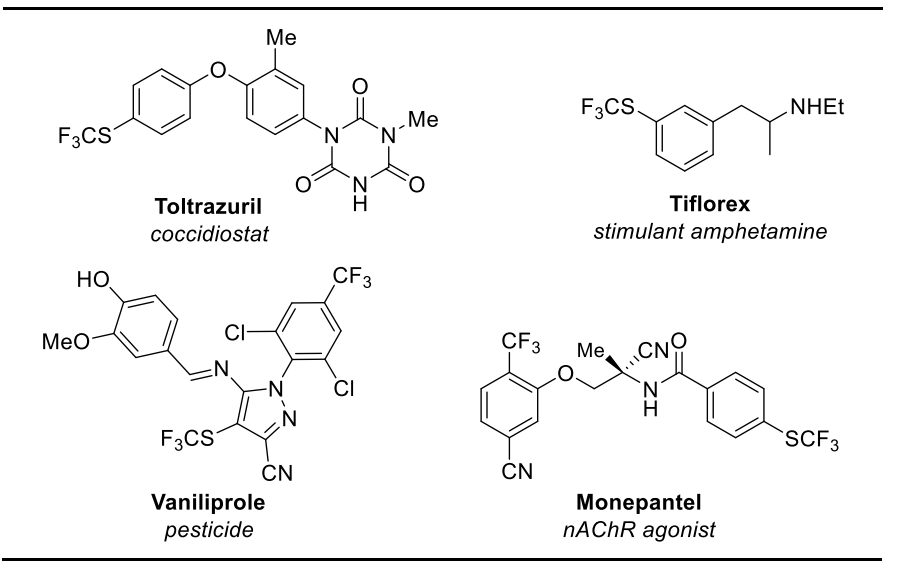

The synthesis of aryl $\mathrm{SCF}_{3}$ compounds has been extensively explored utilizing a range of $\mathrm{M}-\mathrm{SCF}_{3}$ sources $(\mathrm{M}=\mathrm{Ag}, \mathrm{Cu}, \mathrm{Hg}$, $\left.\mathrm{Me}_{4} \mathrm{~N}\right) ;{ }^{1}$ however, many methods require pre-functionalized arenes that are not readily commercially available. ${ }^{2}$ The more desirable cross coupling of readily available aryl halides with anionic $\mathrm{SCF}_{3}$ under mild conditions has received considerable attention. The first broad strategy, disclosed by Buchwald and co-workers, utilizes a palladium(0) catalyst and $\mathrm{AgSCF}_{3}$, and enables the trifluoromethylthiolation of a broad scope of aryl bromides. ${ }^{3}$ Successful transmetalation of $-\mathrm{SCF}_{3}$ to the palladium center was shown to be dependent on activation of the poorly nucleophilic $\mathrm{AgSCF}_{3}$ via formation of a tetraalkyl ammonium iodide -ate complex, a strategy initially introduced by Adams and Clark. ${ }^{4}$ While a useful approach, the complex, air-sensitive catalyst system and high reaction temperatures required are not particularly practical. Schoenebeck and co-workers disclosed a more robust palladium(I) dimer catalyst strategy using $\left[\mathrm{NMe}_{4}\right] \mathrm{SCF}_{3}$ as a source of $-\mathrm{SCF}_{3}$ applicable to both aryl iodides and bromides (Scheme 2a). ${ }^{5,6}$

Scheme 2: Previous Methods for Trifluoromethylthiolation of Aryl Halides

a) Previous Work: Palladium $(0,1)$ Catalysis (Buchwald, Schoenebeck)

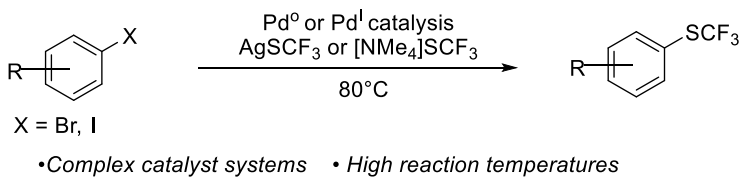

b) Previous Work: Nickel (0) Catalysis (Vicic, Schoenebeck)

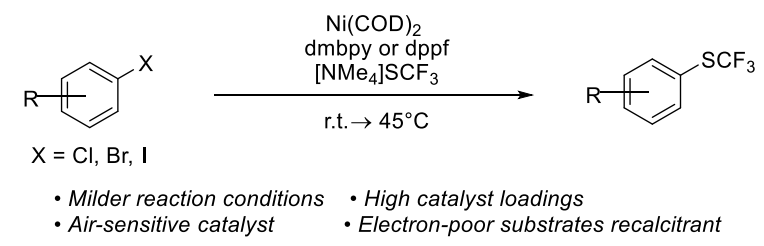

c) This Work: Nickel(II)/ Iridium Metallaphotoredox

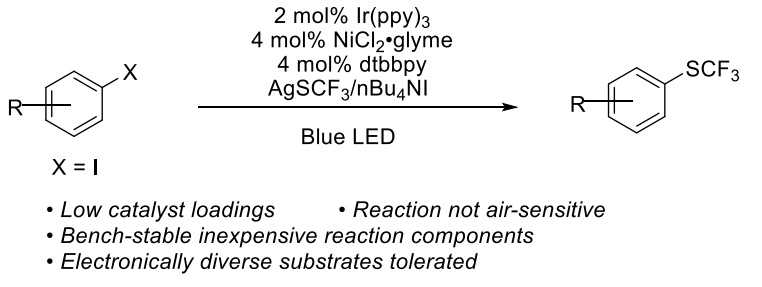

More recently, attention has shifted toward using more abundant nickel catalysis to affect the synthesis of aryl $\mathrm{SCF}_{3}$ compounds. Vicic and co-workers disclosed a room temperature coupling of aryl iodides and bromides using bypridyl ligated $\mathrm{Ni}(0)$; however, the scope was limited to only electron-rich substrates. ${ }^{7}$ Schoenebeck and co-workers demonstrated that using the bulky $1,1^{\prime}$-bis(diphenylphosphino)ferrocene (dppf) ligand to favor a more 
reactive monoligated (dppf) $\mathrm{Ni}(0)(\mathrm{MeCN})$ complex allowed access to aryl chlorides as substrates, but aryl bromides and iodides were found to be unreactive (Scheme $2 \mathrm{~b}$ ). ${ }^{8}$ While these studies are substantial advances in the area of trifluoromethylthiolation of aryl halides using earth-abundant nickel catalysts, the current requirement of high catalyst loadings of the air-sensitive $\mathrm{Ni}(\mathrm{COD})_{2}$ precatalyst limits these transformations to rigorously air-free conditions. Furthermore, they lack the broad substrate scope demonstrated by the previously reported palladium-catalyzed processes.

Our group has recently disclosed a broad, unified method for carbon-heteroatom cross-coupling utilizing a highly reducing $\operatorname{Ir}(\mathrm{ppy})_{3}$ photocatalyst in the presence of a bipyridyl nickel (II) complex, allowing for the cross coupling of aryl halides with oxygen, nitrogen, and sulfur nucleophiles. ${ }^{9}$ The use of $\operatorname{Ir}(\mathrm{ppy})_{3}$ displayed wide functional group tolerance, presumably due to the very low oxidation potential of the photocatalyst excited state $(0.31$ $V$ vs. SCE), which prevents undesirable oxidation of sensitive functional groups. We hypothesized that this would be a viable platform for $-\mathrm{SCF}_{3}$ couplings under mild, air-tolerant conditions employing bench-stable reagents (Scheme 2c).

Employing electron-poor aryl iodide 1a, we found that $\operatorname{Ir}(\mathrm{ppy})_{3}$ in the presence of (dtbbpy) $\mathrm{NiCl}_{2}$ (dtbbpy $=4,4^{\prime}$ - di-tertbutyl-2,2'-bipyridyl) gave high yields of the trifluoromethylthiolation product when employing an in situ generated 1:1 $\mathrm{AgSCF}_{3} / \mathrm{nBu}_{4} \mathrm{NI}$ ate complex as the nucleophile (Table 1, entry 1 ). Electron-rich arene 1b also furnished the desired product in only slightly diminished yield, demonstrating that both electron-rich and electron-poor substrates are viable (entry 2). This reactivity is unique compared to the previous reports with $\mathrm{Ni}(0)$ that are far less reactive towards electron-poor aryl iodides. ${ }^{6}$ Conducting the reaction in the absence of the nickel precatalyst, ligand, photocatalyst, and light all resulted in no product formation (entries 3-6). Only trace product was observed in the absence of $\mathrm{nBu}_{4} \mathrm{NI}$ activator, demonstrating the requirement of in situ generation of the more nucleophilic silver iodo -ate complex (entry 7). Using previously employed $\left[\mathrm{Me}_{4} \mathrm{~N}\right] \mathrm{SCF}_{3}$ in place of $\mathrm{AgSCF}_{3}$ gave no desired product, likely due to the complete decomposition of $\left[\mathrm{Me}_{4} \mathrm{~N}\right] \mathrm{SCF}_{3}$, as observed by ${ }^{19} \mathrm{~F} \mathrm{NMR}$ (entry 8). Utilizing aryl bromides in place of aryl iodides resulted in a lower yield (62\%) for electron-poor aryl bromide 1c and only trace product formation for electron-rich aryl bromide 1d, suggesting that high barriers to oxidative addition for 1d are prohibitive (entries 9-10). These findings are consistent with a $\mathrm{Ni}(\mathrm{I}) / \mathrm{Ni}(\mathrm{III})$ cycle in which rate-limiting oxidative addition to $\mathrm{Ni}(\mathrm{I})$ is in direct competition with other oxidative deactivation processes, such as comproportionation with $\mathrm{Ni}(\mathrm{III})$ or reoxidation by the photocatalyst. ${ }^{10}$ Replacing $\mathrm{NiCl}_{2} \cdot$ glyme with $\mathrm{NiBr}_{2} \cdot$ glyme resulted in lower yields of the desired product, possibly due to a greater driving force for transmetallation of $\mathrm{AgSCF}_{3}$ with dtbbpyNi(I)Cl vs. dtbbpyNi(I)Br (entry 11). A wide range of bipyridyl type ligands work well in this reaction; however, electron-rich ligands tend to give higher yields (entries 12-16). While 4,4'-dimethoxybipyridine gave comparable yields to the standard conditions, higher yields across a broader range of substrates were observed using the optimal conditions with dtbbpy. Since well-established chemistry involving $\mathrm{Ni}(0)$ effects trifluoromethylthiolation, ${ }^{7}$ we wondered if we were generating $\mathrm{Ni}(0)$ via two sequential single electron transfer (SET) events. However, conducting the same reaction using $\mathrm{Ni}(\mathrm{COD})_{2}$ and shielding the reaction from light resulted in no desired product formation, suggesting that a $\mathrm{Ni}(0) / \mathrm{Ni}(\mathrm{II})$ cycle is not active without reductive elimination from $\mathrm{Ni}(\mathrm{II})$ requiring photocatalyst excitation (entry 17 ). However, in the presence of light, employing Doyle's $\mathrm{Ni}(0)$ precatalyst [(TMEDA $) \mathrm{Ni}(0$-tolyl $) \mathrm{Cl}]$ or $\mathrm{Ni}(\mathrm{COD})_{2}$ in place of
$\mathrm{NiCl}_{2} \cdot$ glyme resulted in only slightly diminished yields of the desired product (entries 18-19). These experiments suggest that disproportionation of (dtbbpy) Ni(II)ArX via photocatalyst excitation could generate the active $\mathrm{Ni}(\mathrm{I})$ species. ${ }^{11}$

Table 1: Iridium Photoredox/Ni Dual-Catalyzed Trifluoromethylthiolation of Aryl lodides: Effect of Reaction Parameters
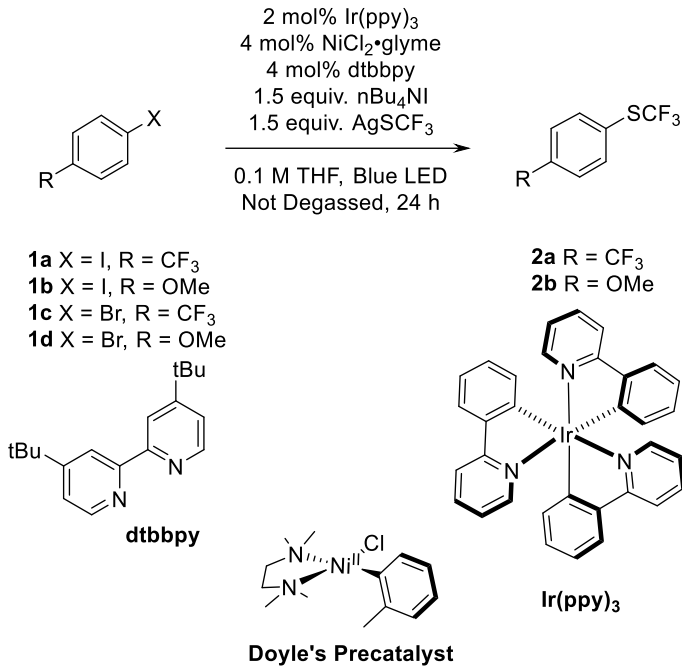

\begin{tabular}{|c|c|c|}
\hline Entry $^{a}$ & $\begin{array}{c}\text { Variation from Standard } \\
\text { Conditions }\end{array}$ & Yield $^{b}$ \\
\hline 1 & 1a, None & $93 \%$ \\
\hline 2 & 1b, None & $85 \%$ \\
\hline 3 & 1a, $\mathrm{No} \mathrm{NiCl}_{2} \cdot$ Glyme & $0 \%$ \\
\hline 4 & 1a, No dtbbpy & $0 \%$ \\
\hline 5 & 1a, No Photocatalyst & $0 \%$ \\
\hline 6 & 1a, No Light & $0 \%$ \\
\hline 7 & 1a, No $\mathrm{nBu}_{4} \mathrm{NI}$ Activator & $9 \%$ \\
\hline 8 & 1a, $\left[\mathrm{Me}_{4} \mathrm{~N}\right] \mathrm{SCF}_{3}$ instead of $\mathrm{AgSCF}_{3}$ Complex & $0 \%$ \\
\hline 9 & 1c, None & $62 \%$ \\
\hline 10 & 1d, None & $2 \%$ \\
\hline 11 & 1a, $\mathrm{NiBr}_{2} \cdot$ Glyme & $78 \%$ \\
\hline 12 & 1a, 4,4'-dMeObpy & $95 \%$ \\
\hline 13 & 1a, 4,4'-dMebpy & $81 \%$ \\
\hline 14 & 1a, bpy & $78 \%$ \\
\hline 15 & 1a, 4,4'-dPhbpy & $74 \%$ \\
\hline 16 & 1a, 4,4'-dCF 3 bpy & $19 \%$ \\
\hline 17 & 1a, $\mathrm{Ni}(\mathrm{COD})_{2}$, No Light & $0 \%$ \\
\hline 18 & 1a, [(TMEDA)Ni(o-tolyl)Cl] & $79 \%$ \\
\hline 19 & 1a, $\mathrm{Ni}(\mathrm{COD})_{2}$ & $74 \%$ \\
\hline
\end{tabular}

a) Reactions conducted in a HepatoChem PhotoRedOx box with $440 \mathrm{~nm}$ Kessil LED at $0.3 \mathrm{mmol}$ scale, without cooling (internal reaction temperature $=55^{\circ} \mathrm{C}$ ). b) Yields determined by ${ }^{19} \mathrm{~F}$ NMR analysis using 1,4-difluorobenzene as an internal standard.

Having established that light input is required for productive reactivity, we wondered whether the reaction proceeds via a closed cycle with the iridium photocatalyst or if the photocatalyst instead 
initiates a self-sustaining $\mathrm{Ni}(\mathrm{I}) / \mathrm{Ni}(\mathrm{III})$ cycle. A quantum yield of 1.5 was measured at short time points $(5,10$, and $20 \mathrm{~min})$, revealing that a thermal $\mathrm{Ni}(\mathrm{I}) / \mathrm{Ni}(\mathrm{III})$ cycle is a substantial component of the observed reactivity (Scheme 3, see Supporting Information for details). ${ }^{10,12}$ As greater than one turnover per photon was observed, it is unlikely that reductive elimination arises from an excited state $\mathrm{Ni}$ (II) complex; the quantum yield for such a reaction theoretically cannot exceed one, requiring photonic input for each catalytic turnover. ${ }^{11}$

Scheme 3: Quantum Yield

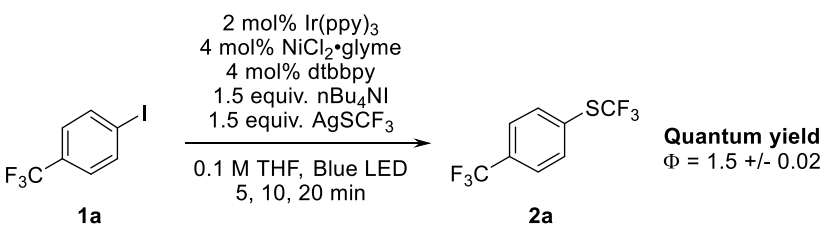

Previous studies on photoredox $\mathrm{Ni}(\mathrm{I}) / \mathrm{Ni}(\mathrm{III})$ catalytic cycles demonstrated that higher catalytic efficiency is achieved at lower nickel concentrations. This is a consequence of deleterious bimetallic comproportionation reactions that lead to off-cycle $\mathrm{Ni}(\mathrm{II})$ complexes at higher catalyst concentrations. ${ }^{12}$ The relationship between nickel catalyst loading and yield at short reaction times was probed (Table 2); we found that varying the nickel/dtbbpy complex loading from $0.5-4$ mol\% gave very similar yields. Higher turnover numbers were observed at lower catalyst loadings (entries 1-3). As the concentration of nickel was increased, lower turnover numbers were observed, until diminished yield at $10 \mathrm{~mol} \%$ indicated the need to keep the nickel concentration low to prevent facile deactivation by $\mathrm{Ni}(\mathrm{I}) / \mathrm{Ni}(\mathrm{III})$ comproportionation (entry 4). ${ }^{10,11}$

Table 2: Effect of Nickel Catalyst Loading on Catalyst Turnover

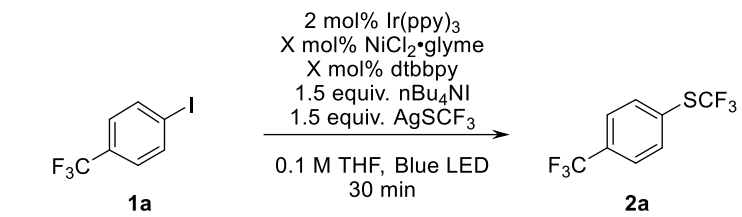

\begin{tabular}{cccc}
\hline Entry $^{a}$ & Nickel/Ligand Loading & Yield $^{b}$ & TON \\
\hline 1 & $0.5 \mathrm{~mol} \%$ & $62 \%$ & 207 \\
2 & $2 \mathrm{~mol} \%$ & $68 \%$ & 57 \\
3 & $4 \mathrm{~mol} \%$ & $66 \%$ & 28 \\
4 & $10 \mathrm{~mol} \%$ & $43 \%$ & 7
\end{tabular}

a) Reactions conducted in a HepatoChem PhotoRedOx box with $440 \mathrm{~nm}$ Kessi LED at $0.3 \mathrm{mmol}$ scale, without cooling (internal reaction temp $=55^{\circ} \mathrm{C}$ ). b) Yields determined by ${ }^{19} \mathrm{~F}$ NMR analysis using 1,4-difluorobenzene as an internal standard.

Although all mechanistic data suggested the formation of an active $\mathrm{Ni}(\mathrm{I})$ species, we wondered if this species arose via photocatalytic single-electron reduction of $\mathrm{Ni}(\mathrm{II})$ or disproportionation of an excited state $\mathrm{Ni}(\mathrm{II})$ species via triplet sensitization. A screen of homoleptic iridium photocatalysts with similar triplet energies (Table 3, See Supporting Information for photocatalyst structures) demonstrated that photocatalysts with high $\operatorname{Ir}(\mathrm{III})^{*} / \operatorname{Ir}(\mathrm{IV})$ reduction potentials and lower $\operatorname{Ir}(\mathrm{IV}) / \operatorname{Ir}(\mathrm{III})$ oxidation potentials gave the highest yields, regardless of their triplet energies (entries 1-3). Utilizing a phenazine-based photocatalyst with a much lower oxidation potential resulted in low yield of the desired product (entry 4). A phenoxazine-based photocatalyst designed to mimic $\operatorname{Ir}(\mathrm{ppy})_{3}$ in both redox properties and triplet energy resulted in nearly identical yields as those obtained from the optimal conditions (entry 5).

Our current hypothesis is that the reduction of (dtbbpy) $\mathrm{Ni}(\mathrm{I}) \mathrm{Cl}$ from (dtbbpy) $\mathrm{Ni}(\mathrm{II}) \mathrm{Cl}_{2}(-1.34 \mathrm{~V} \text { vs. SCE })^{13}$ by the $\operatorname{Ir}(\mathrm{III})^{*}$ excited state is thermodynamically favorable for all catalysts tested. However, photocatalysts with higher $\operatorname{Ir}(\mathrm{IV})$ oxidation potentials are more effective at reoxidation of $\mathrm{Ni}(\mathrm{I})$, thus depleting the active $\mathrm{Ni}(\mathrm{I})$ species in solution, resulting in lower yields. While reoxidation of $\mathrm{Ni}(\mathrm{l})$ depletes the active catalyst, it is likely required for photocatalyst turnover and regeneration of the active catalyst, demonstrated by the low yield observed with phenazine photocatalyst, which is likely not oxidizing enough to reoxidize $\mathrm{Ni}(\mathrm{I})$ (Table 3, entry 4). Based on the above mechanistic studies, we believe that the photocatalyst reduces $\mathrm{Ni}(\mathrm{II})$ to a $\mathrm{Ni}(\mathrm{I})$ complex via single-electron transfer (SET) rather than a triplet sensitization manifold. However, without being able to isolate $\mathrm{Ni}(\mathrm{II})$ or $\mathrm{Ni}^{\prime}\left(\mathrm{SCF}_{3}\right)$ bipyridine complexes for stoichiometric studies ${ }^{14}$ it is unclear which nickel species is reduced by the photocatalyst and at what stage of the catalytic cycle transmetalation occurs.

Table 3: Photocatalyst Screen: Reduction vs. Triplet Sensitization

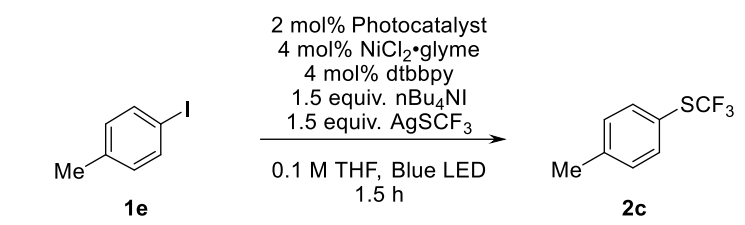

\begin{tabular}{|c|c|c|c|c|c|}
\hline Entry $^{a}$ & Photocatalyst & $\begin{array}{c}E^{0} \\
\left({ }^{2} P C^{++} /\right. \\
\left.P C^{*}\right)\end{array}$ & $\begin{array}{c}E_{1 / 2} \\
\left({ }^{2} P C^{++}\right. \\
P C)\end{array}$ & $\begin{array}{c}E_{\text {Triplet }} \\
\text { kcal/ } \\
\text { mol }\end{array}$ & Yield $^{b}$ \\
\hline 1 & $\operatorname{Ir}(\text { ppy })_{3}{ }^{15}$ & $-1.77 \mathrm{~V}$ & $+0.73 \mathrm{~V}$ & 55.2 & $56 \%$ \\
\hline 2 & $\operatorname{Ir}(\mathrm{p}-\mathrm{Fppy})_{3}{ }^{15}$ & $-1.60 \mathrm{~V}$ & $+0.97 \mathrm{~V}$ & 58.6 & $45 \%$ \\
\hline 3 & $\operatorname{Ir}(\mathrm{dFppy})_{3}{ }^{15}$ & $-1.44 \mathrm{~V}$ & $+1.13 \mathrm{~V}$ & 60.1 & $10 \%$ \\
\hline 4 & Phenazine $\mathrm{PC}^{16}$ & $-1.67 \mathrm{~V}$ & $+0.21 \mathrm{~V}$ & 43.8 & $7 \%$ \\
\hline 5 & Phenoxazine $\mathrm{PC}^{16}$ & $-1.80 \mathrm{~V}$ & $+0.65 \mathrm{~V}$ & 56.5 & $58 \%$ \\
\hline
\end{tabular}

a) Reactions conducted in a HepatoChem PhotoRedOx box with $440 \mathrm{~nm}$ Kessil LED at $0.3 \mathrm{mmol}$ scale, without cooling (internal reaction temp $=55^{\circ} \mathrm{C}$ ). b) Yields determined by ${ }^{19} \mathrm{~F}$ NMR analysis using 1,4-difluorobenzene as an internal standard.

The light dependence of the reaction was examined using on/off experiments to assess the lifetime of the $\mathrm{Ni}(\mathrm{l})$ active catalyst. In the absence of light, the reaction rapidly stalled, demonstrating the short lifetime of the active $\mathrm{Ni}(\mathrm{I})$ species (See Supporting Information). This finding, combined with the quantum yield not greatly exceeding one, indicates that the active nickel catalyst rapidly undergoes deactivation, likely to a $\mathrm{Ni}(\mathrm{II})$ species via $\mathrm{Ni}(\mathrm{I}) / \mathrm{Ni}(\mathrm{III})$ comproportionation or $\operatorname{Ir}(\mathrm{IV})$ reoxidation. This establishes the importance of perpetual re-formation of the active catalyst via the photocatalyst cycle.

With optimized reaction conditions for trifluoromethylthiolation, we set out to explore the substrate scope (Scheme 4). A range of both electronically neutral (-Me), electronwithdrawing $\left(-\mathrm{CF}_{3},-\mathrm{CN},-\mathrm{CO}_{2} \mathrm{Et},-\mathrm{F}\right)$ and electron-donating $(-\mathrm{OBn})$ substituents are well tolerated at all positions on the aryl ring, res- 


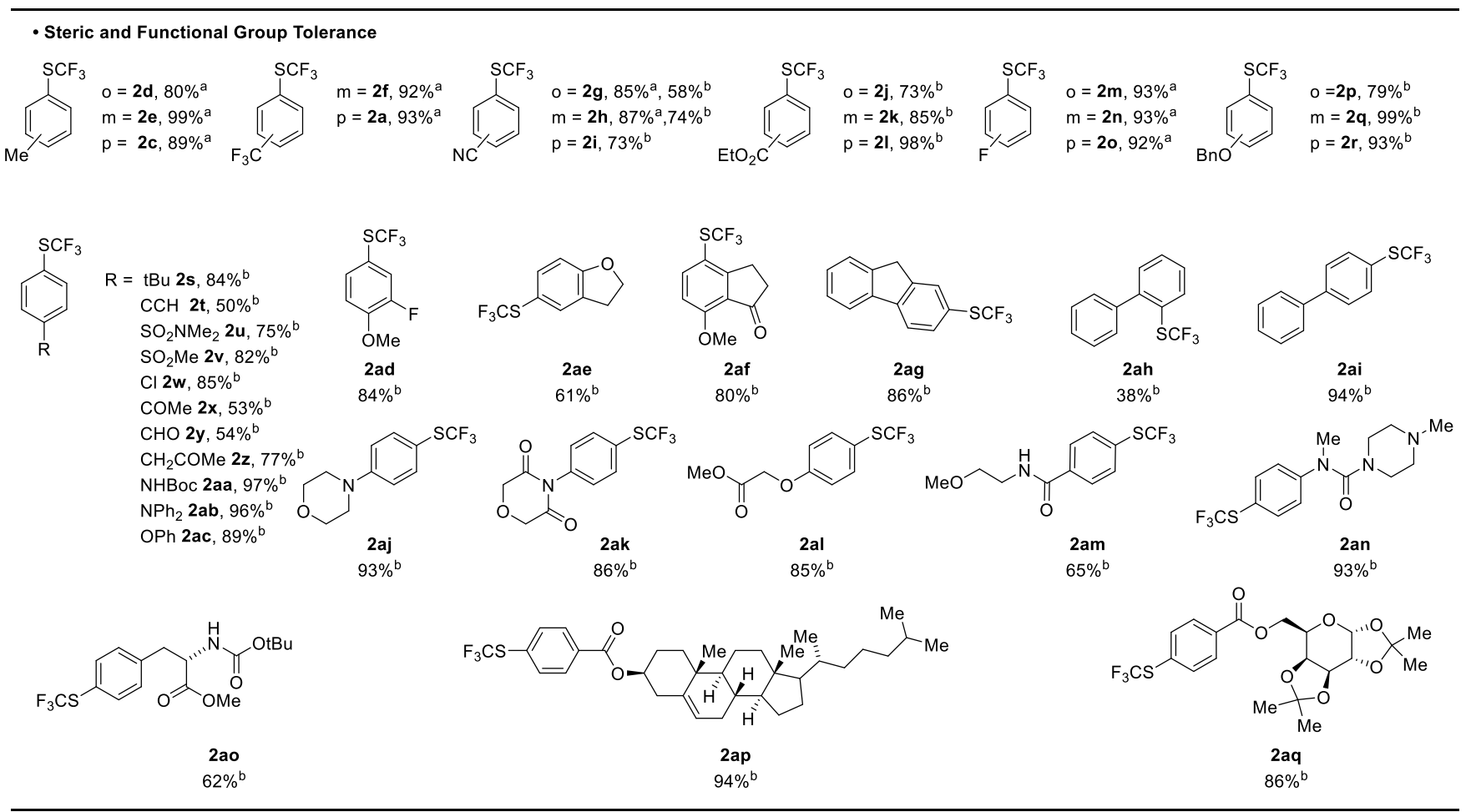

- Heterocycle Functionalization and Medicinally Relevant Scaffolds

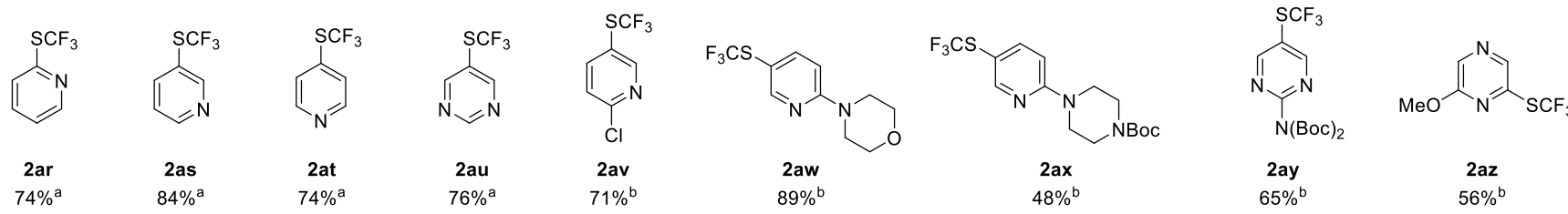

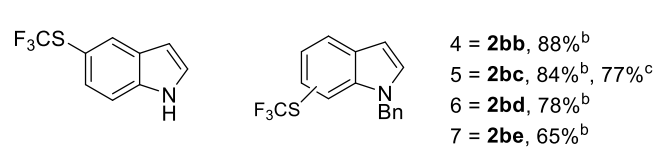

2ba

$70 \%^{a}$<smiles>FC(F)(F)c1ccc2occc2c1</smiles>

2bk $88 \%^{\mathrm{a}}, 76 \%^{\mathrm{b}}$

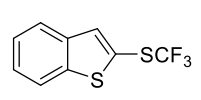

2bl
$85 \%^{a}, 50 \%{ }^{b}$<smiles>[Mg]c1cccc2[nH]ccc12</smiles>

2 bf $64 \%^{\mathrm{b}}$<smiles>FC(F)(F)c1cnc2[nH]ccc2c1</smiles>

2 bg $97 \%^{\mathrm{b}}$

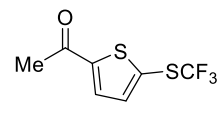

$\mathbf{2 b m}$
$75 \%^{\mathrm{a}}$<smiles>Cn1c(=O)sc2cc(S(F)(F)F)ccc21</smiles>

2bn<smiles></smiles>

2bh
$68 \%^{\mathrm{b}}$<smiles>[AsH3+]c1cn[nH]c1</smiles><smiles></smiles>

$\begin{array}{cc}\mathbf{2 b i} & \mathbf{2 b j} \\ 77 \%^{\mathrm{b}} & 50 \%^{\mathrm{a}}\end{array}$<smiles>Cc1nc2ccc(S(F)(F)F)cc2s1</smiles>

2bo $82 \%^{a}, 74 \%^{b}$

a) Reactions conducted in HepatoChem PhotoRedOx box with $440 \mathrm{~nm}$ kessil LED without the cooling fan (internal reaction temp. $=55^{\circ} \mathrm{C}$ ). Reactions conducted on $0.3 \mathrm{mmol}$ scale for NMR yields and $0.5 \mathrm{mmol}$ scale for isolations a) Yield determined by ${ }^{19} \mathrm{~F}$ NMR analysis with trifluorotoluene as an internal standard for volatile compounds. b) Isolated yield

-ulting in only slightly diminished yield for more sterically hindered ortho-substituted substrates $\mathbf{2 a - 2 r}$. A wide range of functionality is tolerated in the 4-position including terminal alkynes 2t, sulfonamides $2 \mathbf{u}$, sulfones $\mathbf{2 v}$, chlorides $\mathbf{2} \mathbf{w}$, aldehydes $\mathbf{2 y}$, ketones $\mathbf{2 x}, \mathbf{2 z}$, protected amines $\mathbf{2} \mathbf{a} \mathbf{a}-\mathbf{2} \mathbf{a b}$, and phenyl ethers 2ac. Substrates bearing multiple ring substitutions and orthogon- -al electronic affects are also readily functionalized (2ad-2af). Biaryl systems are well tolerated (2ag-2ai); however, sterically hindered 2 ah resulted in diminished yield. A range of medicinally relevant moieties including morpholines, diketomorpholines, acetate-protected phenols, amides, ureas and protected amino acids are all viable functionality in this transformation (2aj-2ao). 
Complex natural products such as cholesterol- and sugarcontaining scaffolds are also readily functionalized using this method (2ap-2aq).

Upon exploration of the heterocycle scope, we observed that all positions of pyridine are readily functionalized (2ar-2at). Substituted pyridines, pyrimidines, and pyrazines 2au-2az are suitable coupling partners. Unprotected 5 -iodoindole $\mathbf{2 b a}$ was readily functionalized; however, protecting the indole nitrogen with commonly used benyzl $(\mathrm{Bn})$ or Boc protecting groups allowed for functionalization of all positions of indole in high yields (64-97\% yield) including an aza-indole $\mathbf{2 b b - 2 b g}$. Protected imidazoles and pyrazoles, which are important scaffolds in medicinal chemistry, are also viable substrates $\mathbf{2 b h} \mathbf{- 2} \mathbf{b j}$. Other important medicinal scaffolds including benzofuran, benzothiopene, thiophene, benzothiazalone, benzothiazole, and Uracil all resulted in the formation of desired $-\mathrm{SCF}_{3}$ products in $50-90 \%$ yields (2bk-2bp). The reaction is also readily scalable, demonstrated by a gram scale $(3 \mathrm{mmol})$ reaction furnishing $\mathbf{2 b c}$ in $77 \%$ isolated yield (Scheme 5). This methodology is amenable to late-stage functionalization, as exemplified by the trifluoromethythiolation of aryl iodide $\mathbf{2 b q}$ to access (racemic)Monepantel (2br), an aryl $\mathrm{SCF}_{3}$ containing organic althelmintic (Scheme 6). ${ }^{17}$ The broad functional group tolerance, scalability, and demonstration of late-stage functionalization of complex drug scaffolds highlights the possibility for wide utility of this reaction in the drug discovery process.

Scheme 5: Reaction Scalability

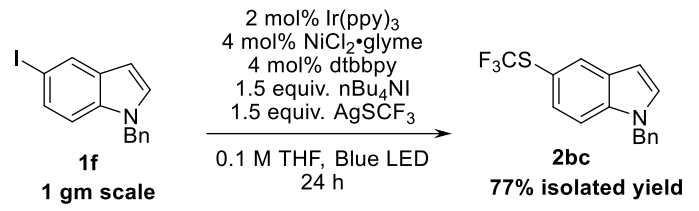

Scheme 6: Synthesis of (Racemic)-Monepantel via Late-Stage Functionalization of $\mathbf{2 b q}$

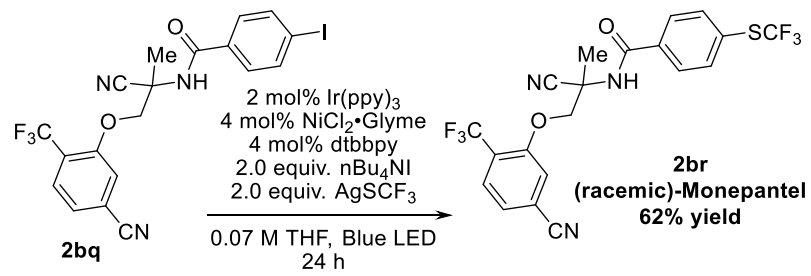

In summary, we have developed a $\operatorname{Ir}(\mathrm{III}) / \mathrm{Ni}(\mathrm{II})$ metallophotoredox strategy for the trifluoromethylthiolation of (hetero)aryl iodides that employs bench-stable, commercially available components and does not require rigorous exclusion of air or moisture. The reaction has a broad substrate scope, tolerating a wide range of medicinally relevant scaffolds and allowing for its use in late-stage functionalization to access Monepantel as a racemate. Preliminary mechanistic studies suggest that the facile reduction of a $\mathrm{Ni}(\mathrm{II})$ precatalyst by $\operatorname{Ir}(\mathrm{ppy})_{3}$ likely generates a reactive $\mathrm{Ni}(\mathrm{I})$ species that can undergo a $\mathrm{Ni}(\mathrm{I}) / \mathrm{Ni}(\mathrm{III})$ photochemically sustained cycle. We envision application of this strategy to other nucleophiles upon further study.

\section{ASSOCIATED CONTENT Supporting information}

The Supporting Information is available free of charge.

\section{AUTHOR INFORMATION}

\section{Corresponding Authors}

*Email: chris.gravatt@astrazeneca.com (C. S. Gravatt)

*Email: avipsa.ghosh1@astrazeneca.com (A. Ghosh)

\section{ORCID}

Jeffrey W. Johannes: 0000-0001-7242-6682

Avipsa Ghosh: 0000-0003-3786-0453

\section{Present Author Address}

C. S. Gravatt: Bay De Noc Community College, Escanaba, Michigan, United States, chris.gravatt@baycollege.edu

\section{Notes}

The authors declare no competing financial interest.

\section{ACKNOWLEDGMENT}

We thank Dr. Sharon Tentarelli (AstraZeneca) for HRMS analysis and Dr. Randolph Escobar (AstraZeneca) for helpful discussions.

\section{REFERENCES}

1 For Reviews on Trifluoromethylthiolation Reactions (a) Barata-Vallejo, S.; Bonesi, S.; Postigo, A. Late Stage Trifluoromethylthiolation Strategies for Organic Compounds. Org. Biomol. Chem. 2016, 14, 7150-7182. (b) Toulgoat, F.; Alazet, S.; Billard, T. Direct Trifluoromethylthiolation Reactions: The "Renaissance" of an Old Concept: Direct Trifluoromethylthiolation Reactions. Eur. J. Org. Chem. 2014, 12, 2415-2428. (c) Xu, X.-H.; Matsuzaki, K.; Shibata, N. Synthetic Methods for Compounds Having $\mathrm{CF}_{3}-\mathrm{S}$ Units on Carbon by Trifluoromethylation, Trifluoromethylthiolation, Triflylation, and Related Reactions. Chem. Rev. 2015, 115, 731-764. (d) Tlili, A.; Billard, T. Formation of $\mathrm{C}_{-} \mathrm{SCF}_{3}$ Bonds through Direct Trifluoromethylthiolation. Angew. Chem. Int Ed. 2013, 52, 6818-6819.

2 (a) Copper-Catalyzed Trifluoromethylthiolation of Di(Hetero)Aryl- $\lambda 3$-iodanes: Mechanistic Insight and Application to Synthesis of (Hetero)Aryl Trifluoromethyl Sulfides. Adv. Synth. Catal. 2015, 357, 3521-3528. (b) Zhao, M. Cu-Mediated Oxidative Trifluoromethylthiolation of Arylboronic Acids with (Bpy)CuSCF 3 . J. of Fluorine Chem. 2017, 194, 73-79. (c) Zheng, C. Copper(I)Promoted Trifluoromethylthiolation of Arenediazonium Salts with $\mathrm{AgSCF}_{3}$ Tetrahedron Lett. 2019, 60, 1404-1407.

3 Teverovskiy, G.; Surry, D. S.; Buchwald, S. L. Pd-Catalyzed Synthesis of

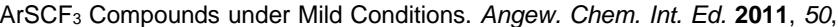
7312-7314

${ }^{4}$ Adams, D. J.; Clark, J. H. Preparation of Trifluoromethyl Aryl Sulfides Using Silver(I) Trifluoromethanethiolate and an Inorganic lodide. J. Org. Chem. 2000, 65, 1456-1460.

5 Tyrra, W.; Naumann, D.; Hoge, B.; Yagupolskii, Y. L. A New Synthesis of Trifluoromethanethiolates-Characterization and Properties of Tetramethylammonium, Cesium and Di(Benzo-15-Crown-5)Cesium Trifluoromethanethiolates. J. Fluorine Chem. 2003, 119, 101-107.

${ }^{6}$ Yin, G.; Kalvet, I.; Schoenebeck, F. Trifluoromethylthiolation of Aryl lodides and Bromides Enabled by a Bench-Stable and Easy-To-Recover Dinuclear Palladium(I) Catalyst. Angew. Chem. Int. Ed. 2015, 54, 6809-6813.

${ }^{7}$ Zhang, C.-P.; Vicic, D. A. Nickel-Catalyzed Synthesis of Aryl Trifluoromethyl Sulfides at Room Temperature. J. Am. Chem. Soc. 2012, 134, 183-185.

${ }^{8}$ Yin, G.; Kalvet, I.; Englert, U.; Schoenebeck, F. Fundamental Studies and Development of Nickel-Catalyzed Trifluoromethylthiolation of Aryl Chlorides: Active Catalytic Species and Key Roles of Ligand and Traceless MeCN Additive Revealed. J. Am. Chem. Soc. 2015, 137, 4164-4172.

${ }^{9}$ Escobar, R. A.; Johannes, J. W. A Unified and Practical Method for CarbonHeteroatom Cross-Coupling Using Nickel/Photo Dual Catalysis. Chem. Eur. J. 2020, 26, 5168-5173.

10 Till, N. A.; Tian, L.; Dong, Z.; Scholes, G. D.; MacMillan, D. W. C. Mechanistic Analysis of Metallaphotoredox $\mathrm{C}-\mathrm{N}$ Coupling: Photocatalysis Initiates and Perpetuates $\mathrm{Ni}(\mathrm{I}) / \mathrm{Ni}(\mathrm{III})$ Coupling Activity. J. Am. Chem. Soc. 2020, 142, 15830-15841.

${ }^{11}$ Ting, S. I.; Garakyaraghi, S.; Taliaferro, C. M.; Shields, B. J.; Scholes, G. D.; Castellano, F. N.; Doyle, A. G. ${ }^{3}$ d-d Excited States of Ni(II) Complexes Relevant to Photoredox Catalysis: Spectroscopic Identification and Mechanistic Implications. J. Am. Chem. Soc. 2020, 142, 5800-5810.

12 Sun, R.; Qin, Y.; Ruccolo, S.; Schnedermann, C.; Costentin, C.; Nocera, D. G. Elucidation of a Redox-Mediated Reaction Cycle for Nickel-Catalyzed Cross Coupling. J. Am. Chem. Soc. 2019, 141, 89-93.

${ }^{13}$ Oderinde, M. S.; Jones, N. H.; Juneau, A.; Frenette, M.; Aquila, B.; Tentarelli,

S.; Robbins, D. W.; Johannes, J. W. Highly Chemoselective Iridium Photoredox 
and Nickel Catalysis for the Cross-Coupling of Primary Aryl Amines with Aryl Halides. Angew. Chem. Int. Ed. 2016, 55, 13219-13223.

${ }^{14}$ Zhang, C.-P.; Brennessel, W. W.; Vicic, D. A. Synthesis and Structure of a Bis-Trifluoromethylthiolate Complex of Nickel. J. Fluorine Chem. 2012, 140, 112-115.

${ }^{15}$ Zuo, Z.; MacMillan, D. W. C. Decarboxylative Arylation of a-Amino Acids via Photoredox Catalysis: A One-Step Conversion of Biomass to Drug Pharmacophore. J. Am. Chem. Soc. 2014, 136, 5257-5260.

16 Du, Y.; Pearson, R. M.; Lim, C.; Sartor, S. M.; Ryan, M. D.; Yang, H.; Damrauer, N. H.; Miyake, G. M. Strongly Reducing, Visible - Light Organic Photoredox Catalysts as Sustainable Alternatives to Precious Metals. Chem. Eur. J. 2017, 23, 10962-10968.

17 Ducray, P.; Gauvry, N.; Pautrat, F.; Goebel, T.; Fruechtel, J.; Desaules, Y.; Weber, S. S.; Bouvier, J.; Wagner, T.; Froelich, O.; Kaminsky, R. Discovery of Amino-Acetonitrile Derivatives, a New Class of Synthetic Anthelmintic

Compounds. Bioorg. Med. Chem. Lett. 2008, 18, 2935-2938. 